\title{
Clinical Study \\ Intestinal Parasitic Infections Among Pregnant Women in Venezuela
}

\author{
Alfonso J. Rodríguez-Morales, ${ }^{1,2}$ Rosa A. Barbella, ${ }^{3,4}$ Cynthia Case, ${ }^{5,6}$ Melissa Arria, ${ }^{7}$ Marisela Ravelo, ${ }^{3}$ \\ Henry Perez, ${ }^{8}$ Oscar Urdaneta, ${ }^{9}$ Gloria Gervasio, ${ }^{6}$ Nestor Rubio, ${ }^{8}$ Andrea Maldonado, ${ }^{8}$ Ymora Aguilera, $^{8}$ \\ Anna Viloria, ${ }^{8}$ Juan J. Blanco, ${ }^{1}$ Magdary Colina, ${ }^{10}$ Elizabeth Hernández, ${ }^{10}$ Elianet Araujo, ${ }^{11}$ \\ Gilberto Cabaniel, ${ }^{3}$ Jesús Benitez, ${ }^{12}$ and Pedro Rifakis ${ }^{9}$
}

${ }^{1}$ Environmental Health, Ministry of Health, Carupano, Sucre 6150, Venezuela

${ }^{2}$ Center for Parasitological Research JWT, University of Los Andes, Trujillo 3102, Venezuela

${ }^{3}$ Salud-Miranda, Miranda 1201, Venezuela

${ }^{4}$ Institute for Pathology, Caracas 1040, Venezuela

${ }^{5}$ Faculty of Health Sciences, University of Carabobo, Valencia 2001, Venezuela

${ }^{6}$ Military Hospital, Caracas 1020, Venezuela

${ }^{7}$ Environmental Health, Ministry of Health, Táchira 5032, Venezuela

${ }^{8}$ Sanitary District Cagijal, Yaguaraparo, Sucre 6150, Venezuela

${ }^{9}$ Perez de Leon Hospital, Caracas 1073, Venezuela

${ }^{10}$ Obstetrics \& Gynecology Service, Maracaibo University Hospital, Maracaibo, Zulia 4004, Venezuela

${ }^{11}$ Chubasquen Hospital, Chubasquen, Portuguesa 3357, Venezuela

${ }^{12}$ Environmental Health, Ministry of Health, Maracay, Aragua 2102, Venezuela

Received 15 April 2005; Revised 30 April 2005; Accepted 7 December 2005

\begin{abstract}
Introduction. Intestinal parasitic infections, especially due to helminths, increase anemia in pregnant women. The results of this are low pregnancy weight gain and IUGR, followed by LBW, with its associated greater risks of infection and higher perinatal mortality rates. For these reasons, in the setting of no large previous studies in Venezuela about this problem, a national multicentric study was conducted. Methods. Pregnant women from nine states were studied, a prenatal evaluation with a coproparasitological study. Univariated and multivariated analyses were made to determine risk factors for intestinal parasitosis and related anemia. Results. During 19 months, 1038 pregnant women were included and evaluated. Intestinal parasitosis was evidenced in $73.9 \%$ : A lumbricoides $57.0 \%$, T trichiura $36.0 \%$, G lamblia $14.1 \%$, E hystolitica $12.0 \%$, N americanus $8.1 \%$, E vermicularis $6.3 \%$, S stercoralis $3.3 \%$. Relative risk for anemia in those women with intestinal parasitosis was $2.56(P<.01)$. Discussion. Intestinal parasitoses could be associated with conditions for development of anemia at pregnancy. These features reflect the need of routine coproparasitological study among pregnant women in rural and endemic zones for intestinal parasites. Further therapeutic and prophylactic protocols are needed. Additional research on pregnant intestinal parasitic infection impact on newborn health is also considered.
\end{abstract}

Copyright (c) 2006 Alfonso J. Rodríguez-Morales et al. This is an open access article distributed under the Creative Commons Attribution License, which permits unrestricted use, distribution, and reproduction in any medium, provided the original work is properly cited.

\section{INTRODUCTION}

The soil-transmitted helminthiases are ancient diseases that continue to cause misery and disability in poor populations. The numbers affected are staggering. About 2 billion harbor these infections worldwide, of whom 300 million suffer associated severe morbidity. Of the total number infected, an estimated 400 millions are school-age children. In 1999, World Health Organization (WHO) estimated that schistosomiasis and soil-transmitted helminthiasis represented more than
$40 \%$ of the disease burden due to all tropical diseases, excluding malaria [1].

Tropical diseases such as malaria, schistosomiasis, intestinal helminths, and filariasis have a dramatic impact on reproductive health. Many cases of unexplained pregnancy loss are due to undiagnosed tropical diseases. Malnutrition or anemia caused by intestinal worms may be worsened by pregnancy and make the pregnancy difficult [2].

In the developing world, young women, pregnant women, and their infants and children frequently experience a 
cycle, where undernutrition (macronutrient and micronutrient) and repeated infection, including parasitic infections, lead to adverse consequences that can continue from one generation to the next. Among parasitic infections, malaria and intestinal helminths coexist widely with micronutrient deficiencies and contribute importantly to anemia and this cycle of retarded growth and development. In somewhat more limited or focal geographic settings, other parasitic diseases (eg, schistosomiasis, filariasis) contribute similarly to this cycle. It is undoubtedly much better to enter a pregnancy free of infection and nutritionally replete than the various alternatives [3].

Intestinal parasitic infections, especially due to the helminths, increase anemia in pregnant women [2-6]. Additionally, hookworm infections induce deficiencies of iron, total energy, protein, and possible folate and zinc $[4,7]$. The results of this are low pregnancy weight gain and intrauterine growth retardation (IUGR), followed by low birth weight (LBW), with its associated greater risks of infection and higher perinatal mortality rates; this has been reported in the majority of studies, although a causal link remains to be completely proven [7-9].

For these reasons, in the setting of no large previous studies in Venezuela about this problem, a national multicentric study was conducted with the objectives to describe preliminarily the epidemiological importance of intestinal parasitosis in pregnant women and its possible impacts.

\section{METHODS}

The study was a transversal analysis of pregnant women attending to prenatal control outpatient health care centers in Venezuela. Pregnant women from fifteen centers located in semi-urban and rural areas of nine states in the country were studied during the period January 2003-July 2004. All women accepted to be studied and included in this study. Women with previous diagnosis of infectious diseases as HIV/AIDS, HBV infection, syphilis, or toxoplasmosis were not enrolled.

Evaluation of those women included, as a part of their routine prenatal control, an initial interrogation, physical examination, and laboratory studies: count of blood cells (CBC) (including thick and thin films, stained with Giemsa), serological screening studies for HIV-1 and -2 (ELISA), HBV (HbsAg and IgM anti-HBc), VDRL, and FTA-ABS, and toxoplasmosis (antibody titers by DAT). For this study, we considered as normal levels of $\mathrm{Hb}$ in women those between $12-16 \mathrm{~g} / \mathrm{dL}$, and between $37-48 \%$ for the hematocrit. An eosinophils proportion up to $4 \%$ was considered normal.

All women were asked for a fresh stool sample each for coproparasitological study. The stool samples were masked, coded, and processed for parasitological examination. All stool samples were processed within 2 hours of collection. Isolation of enteric bacterial and viral pathogens was not studied in these samples. Different stool examinations were used for efficacy in detecting parasites. These were direct wet-mount, formaldehyde-ether sedimentation method and modified acid-fast staining techniques $[10,11]$. The WHO
TABLE 1: Parasite positivity in stool specimens examined from pregnant women studied.

\begin{tabular}{l|rr}
\hline & Number & $(\%)$ \\
\hline Protozoans & & \\
Nonpathogenic & & \\
Entamoeba coli & 44 & 5.7 \\
Endolimax nana & 30 & 3.9 \\
Pathogenic & & \\
Giardia lamblia & 108 & 14.1 \\
Entamoeba histolytica/dispar & 92 & 12.0 \\
Cryptosporidium spp & 2 & 0.3 \\
Helminths & & \\
Ascaris lumbricoides & 437 & 57.0 \\
Trichuris trichiura & 276 & 36.0 \\
Necator americanus & 62 & 8.1 \\
Enterobius vermicularis & 48 & 6.3 \\
Strongyloides stercoralis & 25 & 3.3 \\
\hline
\end{tabular}

Guide for Diagnosis of Intestinal Parasitosis (1994) was used as an identification reference [12]. All data were collected with a unique structured questionnaire, and then this information was integrated after being sent by electronic mail to a central database.

Univariated and multivariated analyses were made to determinate risk factors for intestinal parasitosis and related anemia. Differences concerning paraclinical parameters were evaluated using the Fisher exact test and the chi-squared test. Data were analyzed by SPSS for Windows 10.0 and Epi Info v.6.0. All tests were two-sided with differences considered significant at $P<.05$.

\section{RESULTS}

One thousand thirty eight pregnant women were enrolled in this study. The mean age of this population was $25.5 \pm 6.5$ years old. The mean gestational age at enrollment moment was $28.5 \pm 4.0$ weeks ( $60 \%$ was on the 3 rd trimester).

At clinical evaluations, no apparent significant obstetrical alterations were observed. All women were asymptomatic. All serological studies were negative in all women (HIV, HBV, VDRL, Toxoplasmosis).

Hematological evaluation showed that $65.1 \%$ of women presented anemia. The mean hemoglobin levels were $10.3 \pm$ $0.4 \mathrm{~g} / \mathrm{dL}$, mean hematocrit was $30.6 \pm 1.8 \%$. Eosinophils relative mean proportion was $5.1 \pm 4.2 \%$. Eosinophilia was seen in $22.3 \%$ women. No other alterations were seen in these women.

Intestinal parasitosis was seen in 767 women (73.9\%). From this total, $360(46.9 \%)$ presented infections due to two simultaneous intestinal parasite species, 84 (10.9\%) with three intestinal parasite species, and only 2 women presented infections due to more than three intestinal parasite species $(0.3 \%)$.

In this studied group of women, ten different species of intestinal parasites were found, 2 nonpathogenic protozoans, 3 pathogenic protozoans, and 5 helminths species (Table 1). Ascaris lumbricoides was the most common parasite and 
helminth identified in this study $(57.0 \%)$ followed by Trichuris trichiura $(36.0 \%)$. From those women with dual infection (360), 104 (28.9\%) corresponded to A lumbricoides with Trichuris.

Univariated and multivariated analyses made to assess risk factors for intestinal parasitosis and related anemia only found significance for the presence of intestinal parasitosis as a risk to have anemia during pregnancy, relative risk (RR) was 2.56 (95\% CI 2.13-3.08) (Table 2). When this was adjusted for helminth infection, RR $=1.56$ (95\% CI 1.431.69), and for protozoan infection, $\mathrm{RR}=1.49$ (95\% CI 1.38 1.61). Additionally relative risk was adjusted for helminth species; for A. lumbricoides, RR = 2.01 (95\% CI 1.83-2.20); T trichiura, $\mathrm{RR}=1.18$ (95\% CI 1.08-1.30); Necator americanus, $\mathrm{RR}=1.23$ (95\% CI 1.07-1.41). Finally, relative risk was also adjusted for dual helminth infections and those due to A lumbricoides and T trichiura, RR $=1.99$ (95\% CI 1.83-2.15) and $\mathrm{RR}=1.60$ (95\% CI 1.51-1.70), respectively (Table 2). No association was made with any other variable evaluated.

Finally when compared, levels of hemoglobin, hematocrit, and eosinophils count were significantly different between those women with intestinal parasitic infections (Table 3). With the eosinophilia, we found significance for its presence as marker to be diagnosed as to have intestinal parasitosis during pregnancy $(27.6 \%$ in infected women, $7 \%$ in noninfected women), RR was 1.33 (95\% CI 1.26-1.42; $\left.\chi_{\text {Yates }}^{2}=48.07, P<.0001\right)$.

\section{DISCUSSION}

The burden of disease imposed on helminth-infected girls and women in childbearing age, especially when pregnant, may very well define the single most important contribution of intestinal parasitic infections to the calculation of their global disease burden. Pregnancy requires extra nutrients, especially iron, and produces a "physiological anemia" due to hemodilution $[13,14]$. The anemia results in both decreased appetite and lowered aerobic and physical work capacity, even without the added weight gain to transport-and this is in girls and women who, in the tropics, must often carry their youngest child and the household water supply long distances and also manage to till their fields daily without mechanized equipment. The total amount of work a woman can do in a day definitely decreases when she is anemic, whatever the cause is, and pregnancy plus helminth infections produce a double burden for women in some rural farming communities. [7] Women may even acquire helminth infections in the process of growing the family's food and thus increase their degree of anemia in pregnancy, as for example, in Vietnam, where insufficiently composted human feces may be used as fertilizer on vegetable crops [15].

In this study, where more than a thousand young asymptomatic pregnant women were evaluated, we observed a high prevalence of intestinal parasitosis (more than 70\%), higher than those previously reported for pregnant women in Congo (9\%) [6], Nigeria (12.5\%) [5], Mexico (38.2\%) [16], Brazil (Sao Paulo State, 45.1\%; Rio de Janeiro State,
$69.2 \%)[17,18]$, and Indonesia (69.7\%) [4]. Although current evaluated women were transversally analyzed and more than $65 \%$ had anemia, those with anemia corresponded mainly to infected women (more than $80 \%$ of those with anemia). Almost the half of infected women presented mixed infections, due to two different parasite species which represented a significant risk to have anemia, almost twice than those women who did not. But the most important risk factor to be found with anemia in pregnancy at this series was to be simply presented an intestinal parasitic infection at pregnancy $(\mathrm{RR}=2.56)$, independently if this was due helminths or protozoans. Species adjusted analysis showed that for this study the most important parasite representing a risk to be found with anemia at pregnancy was A lumbricoides (RR $=2.01$ ); the risk of anemia has been frequently reported for $N$ americanus, Ancylostoma duodenale, T trichiura, Strongyloides stercoralis and Enterobius vermicularis [7, 19, 20], but rarely for A lumbricoides [21], which may cause intestinal obstruction, liver abscess, local irritation, and damage with malabsorption as main cellular related events associated with the infection [21, 22]; A lumbricoides plays an important role in precipitating protein-energy malnutrition in undernourished children [23], this infectious disease is a form of malnutrition [21]. Those women infected presented not just a higher frequency of anemia but also significant lower levels of hemoglobin and hematocrit and, obviously, higher levels of eosinophilia. This last, at least in this series, evidenced to be a diagnostic marker for intestinal parasitosis, and with it, this type of infection in pregnant women at endemic zones could be suspected, even if a stool screening is negative (which should be repeated at least 3 consecutive times). Intestinal parasites (especially helminths) can be tissue dwelling or intestinal but all induce a dramatic expansion of the Th2 lymphocyte subset [24, 25]. It remains unclear whether these Th2-derived responses, including IgE, eosinophilia, and mastocytosis are important in the protective immune response to the parasite, or are responsible for immune-mediated pathology, or both [24], but at least is a paraclinical marker of infection.

Given these results, the importance and potential impacts of intestinal parasitosis at pregnancy, such as the anemia, are quietly obvious. Independently to etiology, parasitoses are associated with conditions for development of anemia at pregnancy [7]. This indicates the need for periodical stool examinations during pregnancy as part of routine laboratory test in the prenatal control of women. Considering this, systematic screening and treatment of anemia and associated factors such as intestinal helminthiasis and protozoasis is needed for the pregnant women population, as has been established in other countries [6], to significantly improve the health of mothers and children, because it is undoubtedly much better to enter a pregnancy free of infection and nutritionally replete than the various alternatives. Existing intervention strategies for micronutrient support and for the control of common parasitic infections before or during pregnancy, particularly intestinal parasitosis, should be followed. However, further research to identify barriers and priority approaches to achieving this goal remain very important in 
TABLE 2: Relative risk for anemia at pregnancy according to the presence of intestinal parasitosis.

\begin{tabular}{|c|c|c|c|c|c|}
\hline Variable (risk for anemia) & Anemia & $\begin{array}{c}\text { Tormal } \\
\mathrm{Hb}\end{array}$ & $\mathrm{RR}$ & $\chi_{\text {Yates }}^{2}$ & $P$ \\
\hline \multicolumn{6}{|l|}{ Intestinal parasitosis at pregnancy } \\
\hline Present & 594 & 173 & 2.56 & 194.24 & $<.0001$ \\
\hline Absent & 82 & 189 & - & - & - \\
\hline \multicolumn{6}{|l|}{ Helminth infection at pregnancy } \\
\hline Present & 322 & 61 & 1.56 & 94.63 & $<.0001$ \\
\hline Absent & 354 & 301 & - & - & - \\
\hline \multicolumn{6}{|l|}{ Protozoan infection at pregnancy } \\
\hline Present & 179 & 23 & 1.49 & 59.65 & $<.0001$ \\
\hline \multicolumn{6}{|l|}{ Ascaris lumbricoides infection } \\
\hline Present & 401 & 36 & 2.01 & 233.76 & $<.0001$ \\
\hline \multicolumn{6}{|l|}{ Trichuris trichiura infection } \\
\hline Present & 203 & 73 & 1.18 & 11.25 & .0008 \\
\hline Absent & 473 & 289 & - & - & - \\
\hline \multicolumn{6}{|l|}{ Necator americanus infection } \\
\hline Present & 49 & 13 & 1.23 & 4.98 & .0256 \\
\hline Absent & 627 & 349 & - & - & - \\
\hline \multicolumn{6}{|l|}{ Dual helminth infection } \\
\hline Present & 347 & 13 & 1.99 & 235.08 & $<.0001$ \\
\hline Absent & 329 & 349 & - & - & - \\
\hline \multicolumn{6}{|l|}{ A lumbricoides $+T$ trichiura } \\
\hline Present & 106 & 2 & 1.60 & 56.27 & $<.0001$ \\
\hline Absent & 570 & 360 & - & - & - \\
\hline Total & 676 & 362 & - & - & - \\
\hline
\end{tabular}

TABLE 3: Comparisons between levels of hematological laboratory variables in those women with or without intestinal parasitosis (mean \pm $\mathrm{SD})$.

\begin{tabular}{l|ccrr}
\hline & $(n=767)$ Infected & $(n=271)$ Noninfected & F & $P$ \\
\hline Hemoglobin $(\mathrm{g} / \mathrm{dL})$ & $9.6 \pm 0.7$ & $11.7 \pm 0.4$ & 2185.89 & $<.0001$ \\
Hematocrit $(\%)$ & $29.9 \pm 1.2$ & $34.7 \pm 1.8$ & 2416.68 & $<.0001$ \\
Red cells count $\left(\times 10^{6} / \mathrm{mm}^{3}\right)$ & $4.1 \pm 0.9$ & $4.2 \pm 0.2$ & 3.29 & .0701 \\
White cells count $\left(\times 10^{3} / \mathrm{mm}^{3}\right)$ & $7.5 \pm 2.9$ & $7.8 \pm 2.2$ & 2.41 & .1209 \\
Neutrophils $(\%)$ & $52.3 \pm 5.8$ & $53.0 \pm 5.5$ & 3.00 & .0837 \\
Lymphocytes $(\%)$ & $33.6 \pm 8.9$ & $34.2 \pm 7.7$ & 0.97 & .3239 \\
Eosinophils $(\%)$ & $8.9 \pm 4.9$ & $1.1 \pm 3.7$ & 571.43 & $<.0001$ \\
Platelets $\left(\times 10^{3} / \mathrm{mm}^{3}\right)$ & $212.8 \pm 28.8$ & $216.2 \pm 36.2$ & 2.42 & .1197 \\
\hline
\end{tabular}

resource-poor settings, where targeted public health efforts are required [3].

As has been stated in other studies, it is necessary to modify some preventive measures of information and education and to give specific treatment before the pregnancy in order to increase some of the pregnant women's health indicators. The newborn of mothers with intestinal parasitosis have a greater probability of being born with less weight than what is expected [16], although we did not evaluate this issue on the current study.

These results enhanced the need for wide implementation of intermittent iron and folic acid supplementation as a valid strategy when used as a preventive intervention in prenatal care settings [14]. But that antihelminthic therapy could be given to infected women before conception as public health strategy to improve iron status may be also considered. Additionally once diagnosed, if the woman is on the second or third gestation trimester, it could be treated. In the current study, all women in this condition were treated with mebendazol $500 \mathrm{mg}$ after first trimester, as has been recommend by some authors who consider a possible national strategy for prevention and control is to give a single dose of this drug during the second or third gestation trimesters [26]. 
The current study reflects the need of routine coproparasitological study among pregnant women in rural and endemic zones for intestinal parasites. Even more, further therapeutic and prophylactic protocols are needed. Additional research on pregnant intestinal parasitic infection impact on newborn health is on-going.

\section{ACKNOWLEDGMENTS}

This study was partially presented at the 11th International Congress on Infectious Diseases, Cancun, Mexico, March 47, 2004. This study was partially supported by the Metropolitan District of Caracas Medical College with a congress travel grant for A J Rodriguez-Morales and a Congress Scholarship from the International Society for Infectious Diseases.

\section{REFERENCES}

[1] WHO. Schistosomiasis and soil-transmitted helminthiasisan unprecedented opportunity for control. In: WHO. Communicable Diseases 2002 - Global defence against the infectious diseases threat. World Health Organization, Geneva, Switzerland, 2003.

[2] Otieno-Nyunya B. Tropical diseases can harm pregnancy. Network. 1999;19(2):5-7.

[3] Steketee RW. Pregnancy, nutrition and parasitic diseases. The Journal of Nutrition. 2003;133(5 suppl 2):1661S-1667S.

[4] Nurdia DS, Sumarni S, Suyoko, Hakim M, Winkvist A. Impact of intestinal helminth infection on anemia and iron status during pregnancy: a community based study in Indonesia. The Southeast Asian Journal of Tropical Medicine and Public Health. 2001;32(1):14-22.

[5] Egwunyenga AO, Ajayi JA, Nmorsi OPG, Duhlinska-Popova DD. Plasmodium/intestinal helminth co-infections among pregnant Nigerian women. Memórias do Instituto Oswaldo Cruz. 2001;96(8):1055-1059.

[6] Kalenga MK, Nyembo MK, Nshimba M, Foidart JM. Étude de l'anémie chez les femmes enceintes et les femmes allaitantes de Lubumbashi (République Démocratique du Congo)[Anemia prevalence in pregnant and breast-feeding women in Lubumbashi (Democratic Republic of the Congo). Impact of malaria and intestinal helminthiasis]. Journal de Gynecologie, Obstetrique et Biologie de la Reproduction. 2003;32(7):647-653.

[7] Stephenson LS, Latham MC, Ottesen EA. Malnutrition and parasitic helminth infections. Parasitology. 2000;121(7):23-38.

[8] Allen LH. Biological mechanisms that might underlie iron's effects on fetal growth and preterm birth. Journal of Nutrition. 2001;131(2S-2):581S-589S.

[9] Khor GL. Update on the prevalence of malnutrition among children in Asia. Nepal Medical College Journal. 2003;5(2):113122.

[10] Ridley DS, Hawgood BC. The value of formol-ether concentration of faecal cysts and ova. Journal of Clinical Pathology. 1956;9(1):74-76.

[11] Casemore DP, Armstrong M, Sands RL. Laboratory diagnosis of cryptosporidiosis. Journal of Clinical Pathology. 1985; 38(12): 1337-1341.

[12] WHO. Medios auxiliaries para el diagnóstico de las parasitosis intestinales. World Health Organization, Geneva, Switzerland, 1994.
[13] Steer PJ. Maternal hemoglobin concentration and birth weight. The American Journal of Clinical Nutrition. 2000;71(5): 1285S-1287S.

[14] Pena-Rosas JP, Nesheim MC, Garcia-Casal MN, et al. Intermittent iron supplementation regimens are able to maintain safe maternal hemoglobin concentrations during pregnancy in Venezuela. The Journal of Nutrition. 2004;134(5):1099-1104.

[15] Humphries DL, Stephenson LS, Pearce EJ, The PH, Dan HT, Khanh LT. The use of human faeces for fertilizer is associated with increased intensity of hookworm infection in Vietnamese women. Transactions of the Royal Society of Tropical Medicine and Hygiene. 1997;91(5):518-520.

[16] Rodriguez-Garcia R, Rodriguez-Guzman LM, SanchezMaldonado MI, Gomez-Delgado A, Rivera-Cedillo R. Prevalencia y factores de riesgo asociados con parasitosis intestinales en mujeres embarazadas y su relación con el peso del niño al nacer [Prevalence and risk factors associated with intestinal parasitoses in pregnant women and their relation to the infant's birth weight]. Ginecología y Obstetricia de México. 2002;70(7):338-343.

[17] Guerra EM, Vaz AJ, de Toledo LA, et al. Helminth and protozoan intestinal infections in pregnant women in their first consultation at Health Centers of the State in the Butanta Subdistrict, Sao Paulo City [in Portuguese]. Revista do Instituto de Medicina Tropical de São Paulo. 1991;33(4):303-308.

[18] Macedo LM, Rey L. Enteroparasitoses em gestantes e puérperas no Rio de Janeiro [Enteroparasitosis in pregnant and post-partem women in Rio de Janeiro]. Cadernos de Saúde Pública. 1996;12(3):383-388.

[19] Layrisse M, Aparcedo L, Martinez-Torres C, Roche M. Blood loss due to infection with Trichuris trichiura. The American Journal of Tropical Medicine and Hygiene. 1967;16(5):613-619.

[20] Lotero H, Tripathy K, Bolanos O. Gastrointestinal blood loss in Trichuris infection. The American Journal of Tropical Medicine and Hygiene. 1974;23(6):1203-1204.

[21] Rosenberg IH, Bowman BB. Impact of intestinal parasites on digestive function in humans. Federation Proceedings. 1984;43(2):246-250.

[22] Beaver PC. Biology of soil-transmitted helminths: the massive infection. Health Laboratory Science. 1975;12(2):116-125.

[23] Ananthakrishnan S, Nalini P, Pani SP. Intestinal geohelminthiasis in the developing world. The National Medical Journal of India. 1997;10(2):67-71.

[24] Allen JE, Maizels RM. Immunology of human helminth infection. International Archives of Allergy and Immunology. 1996;109(1):3-10.

[25] Finkelman FD, Urban JF Jr. The other side of the coin: The protective role of the $\mathrm{T}_{\mathrm{H}} 2$ cytokines. Journal of Allergy and Clinical Immunology. 2001;107(5):772-780.

[26] PAHO. Informe de una reunión de consulta sobre el uso de quimioterapia para el control de la morbilidad debida a nematodos transmitidos por el suelo en humanos. Pan American Health Organization, Washington, DC, 1999. 


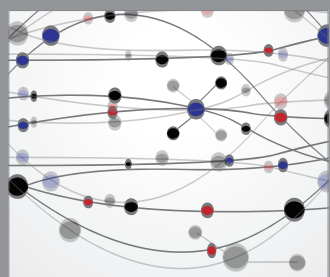

The Scientific World Journal
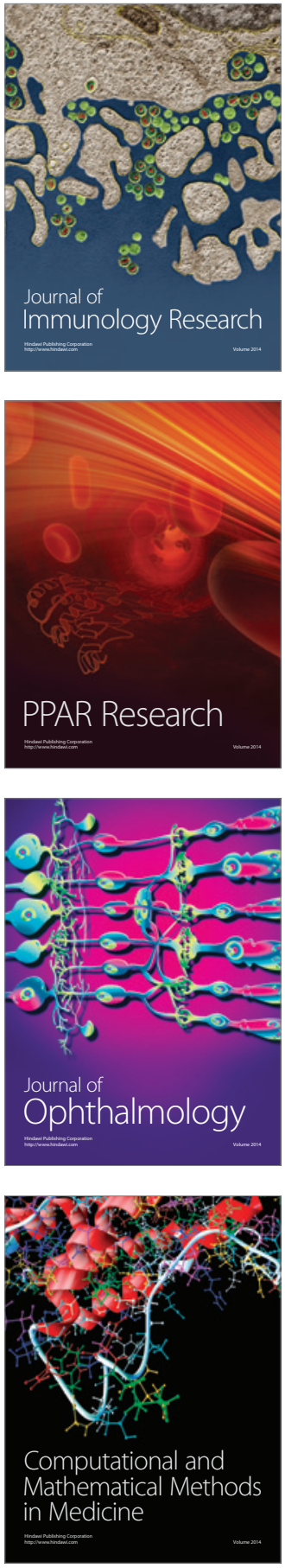

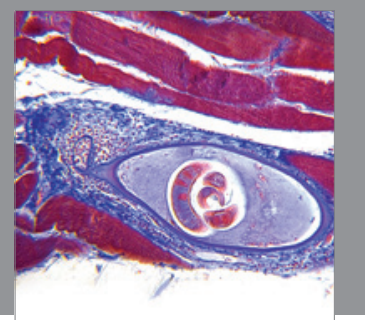

Gastroenterology

Research and Practice
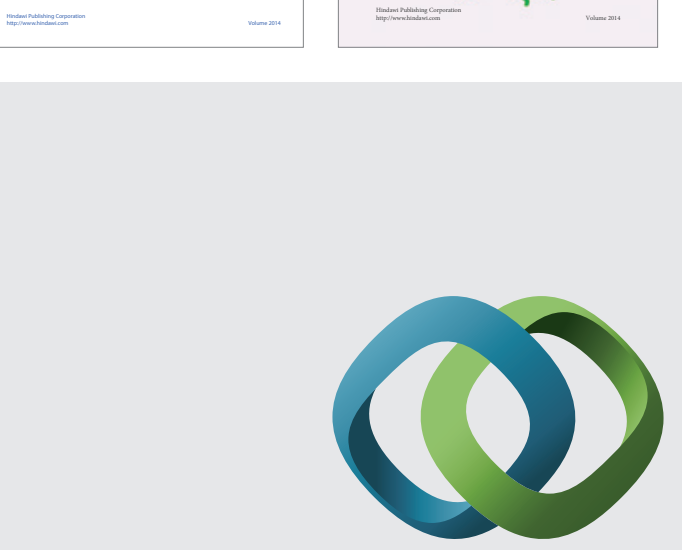

\section{Hindawi}

Submit your manuscripts at

http://www.hindawi.com
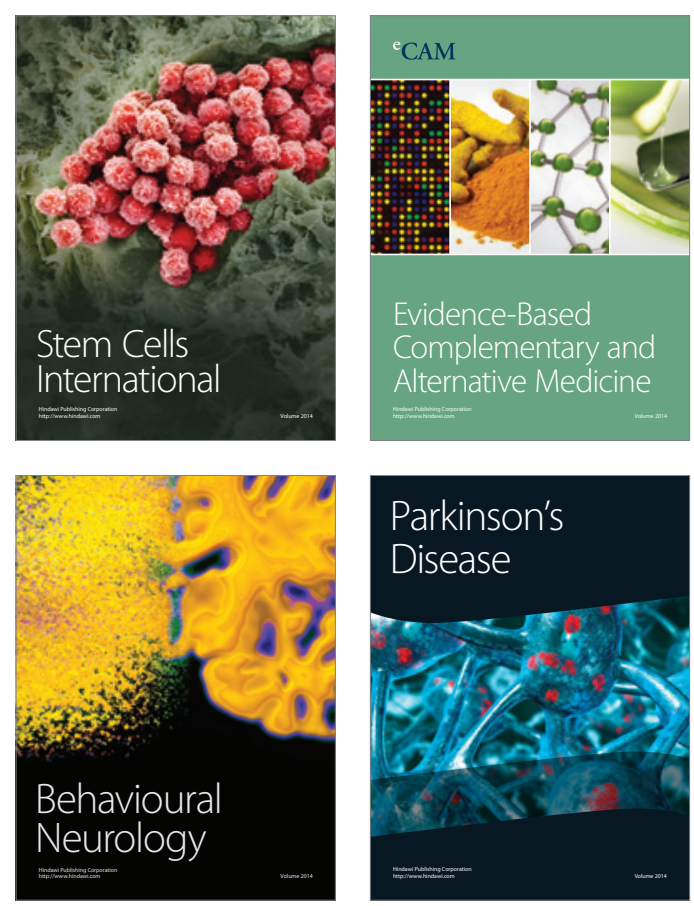

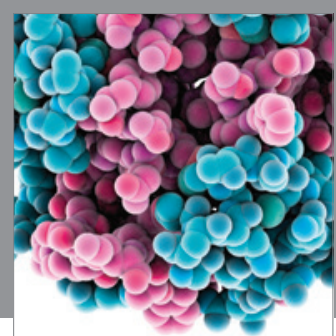

Journal of
Diabetes Research

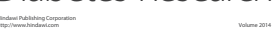

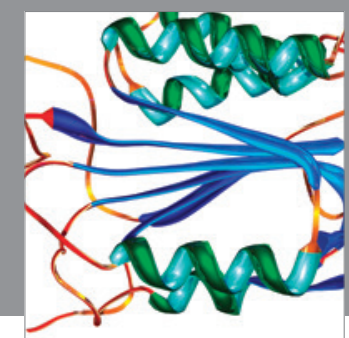

Disease Markers
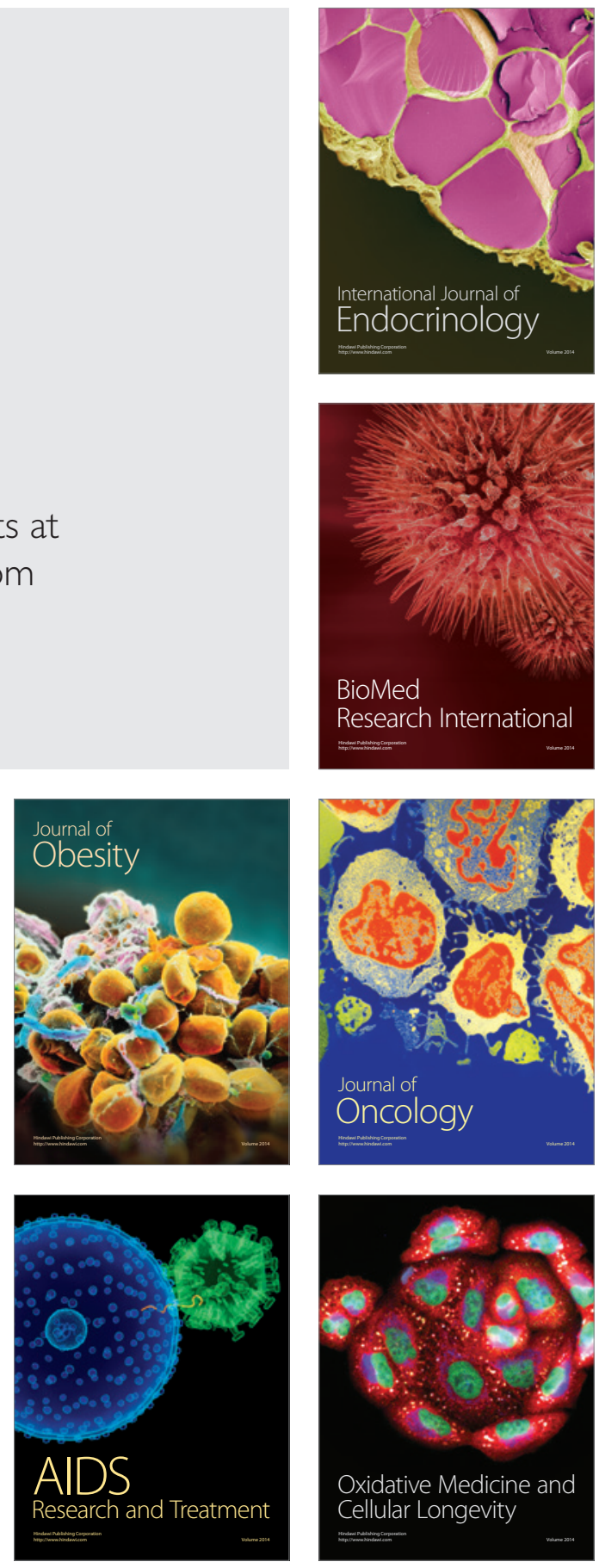